\title{
LA REACTIVIDAD ¿UN IMPERATIVO POLÍTICO? TRANSFORMACIONES HISTÓRICAS DE LAS TEMPORALIDADES EN EL QUEHACER PERIODÍSTICO CHILENO
}

\author{
Is the Reactivity a Political Imperative? \\ Historical Transformations of the Temporalities in Chilean Newsmaking
}

\section{RESUMEN}

En este ensayo, se considera la reactividad periodística como la capacidad práctica y discursiva que tienen los periodistas para actuar rápidamente en respuesta al entorno. Esta idea permite comprender de mejor forma la diversidad histórica de prácticas de mediatización y el desplazamiento temporal entre el "evento" y la noticia. Se propone entonces un recorrido conceptual sobre las temporalidades periodísticas con el fin de rastrear la idea reactividad y sus transformaciones diacrónicas en el quehacer periodístico. Para cuestionar la dimensión política de estas transformaciones, se propone una perspectiva genealógica que abarca una multitud de gestos mediáticos híbridos, sin seguir cronología, dado que esos articulan anacronismos, continuidades e innovaciones.

Palabras claves: Prácticas periodísticas; Temporalidades; Actualización; Crisis.

\section{UNIVERSUM}

Revista de Humanidades y Ciencias Sociales

\author{
ANTOINE FAURE \\ Profesor Asistente, Escuela de \\ Periodismo, USACH. \\ Correo electrónico: \\ antoine.faure@usach.cl
}

ORCID: 0000-0002-9140-5980 ResearchGate: Antoine_Faure3 Scholar.google: https://scholar. google.com/citations?user=E TmeyEAAAAJ\&hl=es\&authuser $=2$ Academia.edu:

Este texto forma parte de la investigación realizada en el marco del FONDECYT de Iniciación $\mathrm{N}^{\circ} 11170348$ titulado "Historia de las temporalidades periodísticas chilenas (1973-2013): otra mirada sobre la dimensión política del periodismo profesional" (2017-2020). 


\begin{abstract}
In this essay, journalistic reactivity is considered as the practical and discursive capacity that journalists have to act quickly in response to the environment. This idea allows us to better understand the historical diversity of mediatization practices and the temporal displacement between the "event" and the news. A conceptual overview is then made on the journalistic temporalities in order to trace the idea of reactivity and its diachronic transformations in newsmaking. In order to question the political dimension of these transformations, a genealogical perspective is proposed that encompasses a multitude of hybrid media gestures, without following chronology, given that these articulate anachronisms, continuities and innovations.
\end{abstract}

Keywords: Journalistic Practices; Temporalities; Updating; Crisis.

Este texto busca rastrear las temporalidades periodísticas chilenas, e identificar las rupturas históricas de la lógica que las ordena. En efecto, la cultura profesional del periodismo occidental se ha construido en torno a un entretejido de prácticas y normas temporales que se despliegan en una "cadena de producción”, como lo muestra el caso británico (Schlesinger, 1977: 35). En ese sentido, se ha intentado buscar en las prácticas y los comportamientos periodísticos chilenos, señales de un cambio más profundo que tiene que ver con la tendencia a la mediatización de las sociedades contemporáneas. Lo trabajamos en el desplazamiento temporal entre el "evento" y la "noticia" (Dayan y Katz, 1992) que, apostamos, se desarrolla en las transformaciones que vive la idea de "reactividad periodística". Por ahora, se abordará esta idea como un objeto que asumimos transversal y poco explorado, y que remite sencillamente a la capacidad de actuar rápidamente en respuesta al entorno.

Para rastrear las transformaciones de esta idea en el quehacer periodístico, buscamos los indicios de un discurso de reactividad en las prácticas y en los enunciados mediáticos. Se comprende entonces la diversidad histórica de prácticas de mediatización, como (...) "las amplias consecuencias de la organización práctica (social, política, cultural y económica) de los medios sobre nuestra vida cotidiana, y más específicamente de la invasiva propagación de los contenidos y de las plataformas mediáticas en todos los 
tipos de contextos y de prácticas" (Couldry y Hepp, 2013: 191). ${ }^{1}$ Referencia prácticas individuales de microblogging, la impresión de una vieja gaceta, la tarea organizacional de fabricación periodística de un diario, un programa de radio o de televisión, la tarea de propagación de un artículo multimedia en el sitio de una empresa mediática $\mathrm{o}$, para dar un último ejemplo, las prácticas sectoriales dirigidas a los medios de comunicación (inspirándose en los mediadriven-politics, teorizados entre otros por Zaller, 1999).

Movilizamos, en este texto, un haz ecléctico de fenómenos y dispositivos "que sirven de mediación a la comunicación humana permitiendo grabar, multiplicar, transmitir, y difundir ideas, frases, sonidos, imágenes u otras percepciones sensoriales" (Citton, 2014: 3), sin enfocarse en un sector mediático o algunas tareas periodísticas en específico: los valores noticiosos, la cobertura de eventos en vivo, el uso de redes sociales virtuales por parte de periodistas, el uso de redes sociales virtuales por personas corrientes, etc. ${ }^{2}$

El afán es claramente teórico: para entender a qué remite la "inmediatez" mediática actual, se hace necesario describir brevemente la metamorfosis diacrónica que vive el discurso de reactividad. Dado que, en las prácticas y los dispositivos mediáticos, se articulan e hibridan gestos mezclando rutinas y espontaneidad; anacronismos, continuidades e innovaciones; es necesario operar idas y vueltas históricas, sin seguir una cronología clásica y privilegiando vaivenes entre las épocas. Se pretende rastrear los sentidos de la "reactividad periodística" que se han disputado; las sedimentaciones y reapropiaciones de estas significaciones; las re-significaciones, las invenciones y experimentaciones.

No se busca aquí un origen, es decir "la esencia exacta de la cosa, su

1 Todas las traducciones son del autor.

2 Estos elementos empíricos provienen de varios proyectos de investigación que llevamos a cabo sobre las rutinas periodísticas chilenas a través de la historia reciente (1953-2013), principalmente desde un diseño metodológico que articula análisis de la morfología y de las materialidades de archivos mediáticos (prensa, televisión y prensa digital) y entrevistas semi-estructuradas con periodistas. Los otros materiales provienen principalmente de trabajo de colegas, historiadores de los medios (Ossandón y Santa Cruz, 1998), sociólogos de la producción de noticias (Salinas y Stange, 2015), etnólogas de las salas de reacción (Küng, 2015; Usher, 2014), economistas (Sunkel y Geoffroy, 2001). 
posibilidad la más pura, su identidad replegada sobre sí misma de manera cuidadosa, su forma inmóvil y anterior a todo lo externo, accidental y sucesivo" (Foucault, 1971: 1006). Sería en vano. La historia de los periódicos ya mostró que la inmediatez deviene de una norma histórica, que imponía plazos como mecanismo de difusión de noticias en el imperio Romano, la China de los Han, en la Venecia del Renacimiento (Stephens, 2012), o a través del Chasqui en el imperio Inca (agregamos). La perspectiva genealógica prohíbe también proyectar el estado de las cosas actuales sobre el pasado y, a la vez, atribuir una teleología tanto tecnológica como institucional sobre el objeto de estudio. Como si emergiera para una meta superior y contenida de manera subrepticia. No cuestionamos, aquí, la verdad de la representación reactiva de los periodistas, sino la transformación del sentido de esta reactividad a lo largo de los dos siglos pasados, y a partir del caso chileno. Esta metamorfosis se rastrea en tres etapas (en los puntos 2, 3 y 4 del texto), que abordamos después de plantear el problema en las confluencias históricas del haz ecléctico de dispositivos comunicacionales (1). Terminaremos en clave de discusión conclusiva, con un desarrollo sobre la relevancia y el devenir de esta idea de "reactividad periodística", sondeando su dimensión política.

\section{CONFLUENCIAS HISTÓRICAS HACIA EL PROBLEMA DE LA REACTIVIDAD PERIODÍSTICA}

Este objetivo se formuló al momento de una observación peculiar. El 5 de enero 2016 a las 20:49, hora francesa, ${ }^{3}$ aparece un mensaje vertiginoso de la cuenta de Twitter@FelipeParadaM ${ }^{4}$ que alerta sobre la presentación de un proyecto de ley propuesto por los diputados chilenos Hasbún, Ulloa y Urrutia

\footnotetext{
3 En aquel momento, vivíamos en Francia.

4 El usuario de Twitter se define como: "Proyecto de Periodista, 23 años, Recoletano, militante, ex dirigente estudiantil, Director@Fund-pelontxaro, Tesorero@codejuci, Vocero @ nuevorecoleta, \#NoFumo". Desde esta identidad polifónica, intenta proyectar su trabajo periodístico y político como principal imagen.
} 
(UDI). ${ }^{5}$ Este último propone sancionar "a quién enaltezca, niegue o minimice la figura del Presidente de la República o gobierno que haya quebrantado la Constitución y las leyes" (figura 1$){ }^{6}$

Si bien el componente ideológico es llamativo, lo decisivo aquí es que el mensaje se fabricó y se posteó inmediatamente, apenas unos minutos después de la presentación del proyecto de ley. Aún ningún representante del ciberperiodismo había publicado la noticia. Las cuentas Twitter de El Mercurio, La Tercera, Radio Cooperativa o El Mostrador (entre otros), transmitían la noticia bruta cerca de una hora después, antes de editarla en sus sitios web. Estos medios parecieran superados por la instantaneidad del microblogging.

En este ejemplo peculiar, se observan 3 características temporales de la mediatización: una reducción de la relación mediática entre tiempo y espacio; la competencia por la primacía noticiosa, entre medios tradicionales y redes sociales virtuales; $y$, la fuerza de la inmediatez para mediatizar las novedades. En el caso de la relación que la mediatización tiene con el tiempo, se generaría un desplazamiento temporal entre el "evento" y la noticia.

5 Unión Democrática Independiente, partido político de derecha que tiene origen en los partidarios del General Augusto Pinochet, específicamente el abogado e ideólogo del régimen autoritario, Jaime Guzmán.

6 Al denunciar "gobiernos que (...) generaron en el seno de la sociedad chilena desencuentro, violencia y animosidades profundas, por ejemplo, el que presidió el señor Salvador Allende Gossens entre los años 1970 y 1973", el proyecto de ley sigue el trabajo de endeudamiento histórico de la izquierda política, tratando de ahogar toda alternativa de sociedad en un relato de reconciliación. Relata la ruptura del Estado de Derecho situándola durante el gobierno de la UP, y disculpando por lo tanto el régimen autoritario de Pinochet. 
Figura 1: La alerta twitter de Felipe Parada (05 de enero de 2016).

\section{URGENTE: Hasbun/Urrutia/Ulloa quieren castigar con presidio a quienes enaltezcan a Allende goo.gl/1uqPtF}

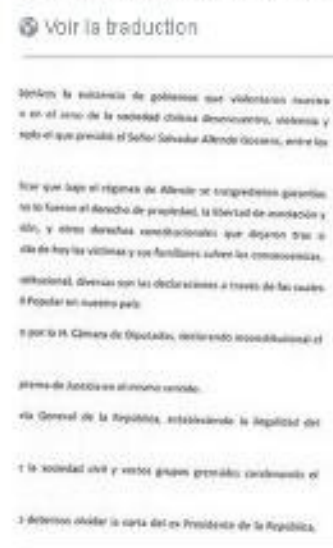

ury.

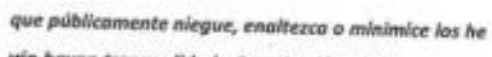
wio hayan trosgredido la Constitucidin Polltica y las iej i menar en su grado minimo y multa de 5 Unidades $\mathrm{Tr}$.

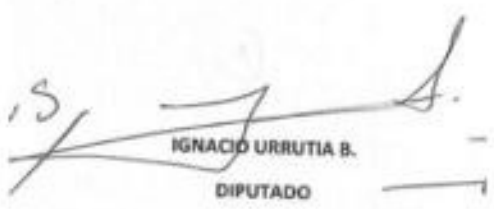

Fuente: https://twitter.com/FelipeParadaM

No obstante, el problema de desfase entre el acontecimiento y la circulación de la nota no es nuevo. Ya se observa en La Aurora de Chile, considerado como el primer diario de prensa chilena. Publica una carta el 10 de septiembre de 1812, sobre los "posibles escenarios bélicos a los cuales se enfrentará Cádiz", carta que fue escrita el 28 de febrero del mismo año (figura 2) 7 y necesitó seis meses para cruzar el océano hasta llegar a la imprenta de fray Camilo Henríquez. El uso del futuro en el primer párrafo parecería, hoy, fuera del realismo periodístico, pero, en este ejemplo, lo novedoso de la noticia no tiene que ver con el "evento" al que se refiere sino con la temporalidad social de la noticia. Remite a la idea de periodismo como construcción discursiva de la noticia (Alsina, 1989) y del presente (Gomis, 1991).

7 Ya en su primer número, publicado el 13 de febrero de 1812, se encuentra una nota sobre la coronación del rey de Haití que data de 1811. 
Figura 2: Extracto de la Aurora de Chile (10 de diciembre 1812)

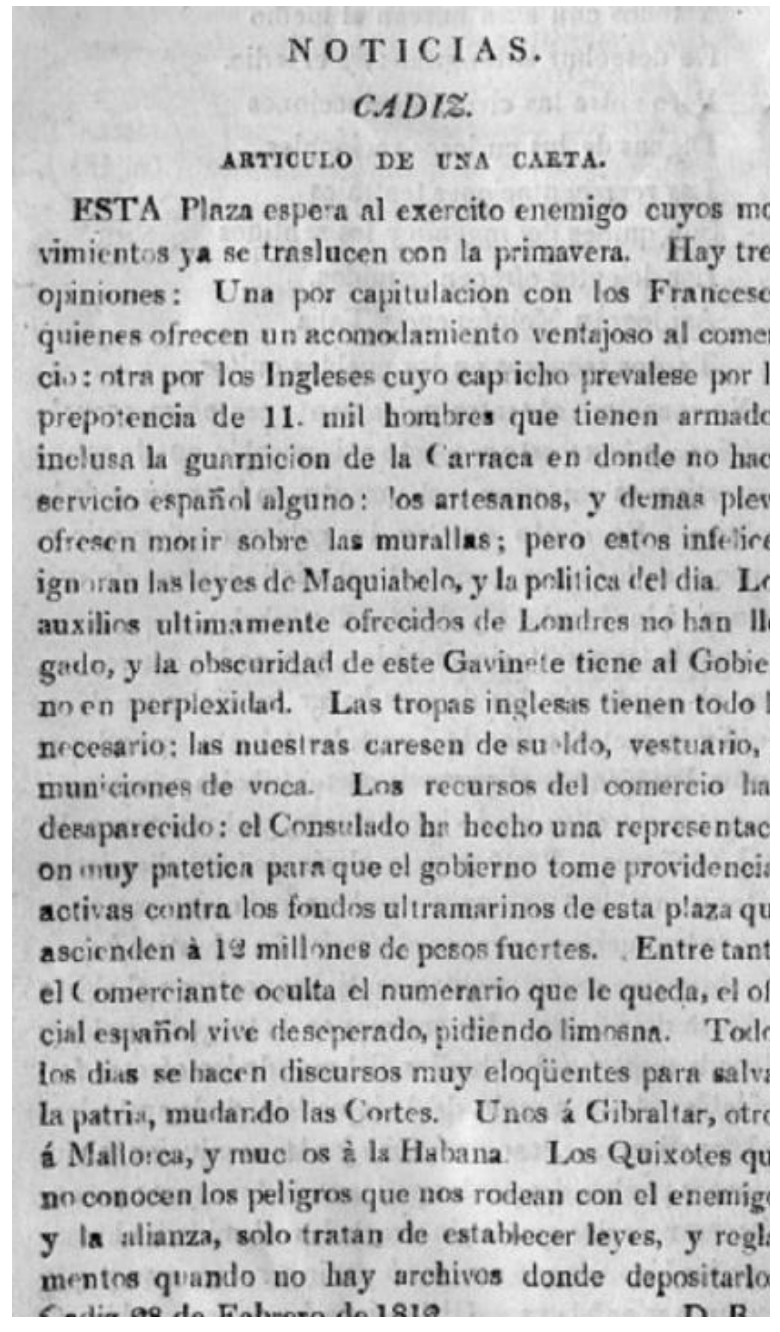

Fuente: http://www.memoriachilena.cl/602/w3-article-70818.html

Por otra parte, las representaciones del rol de periodista han comúnmente mostrado a un reportero reactivo, es decir dispuesto a llevar su chaqueta de día o de noche, para perseguir una noticia: le demandará tiempo, compromiso, perseverancia y una buena dosis de habilidad. Muchos productos culturales vehiculan esta imagen: el comic Tintín (1930-1986), la película Todos los hombres del presidente (1976) o la serie The Wire (2006-2010) en su quinta y 
última temporada. ${ }^{8}$ Se confirma en Chile, en la serie de ficción televisiva Bala Loca (2016) o en los testimonios de periodistas. ${ }^{9}$

Esta representación está vigente en el imaginario periodístico actual. Así, Javier Urrutia (director ejecutivo de Canal 13) revela la multiplicidad, la rapidez y la simultaneidad de las tareas en una empresa mediática, al explicar las reformas de 2018 para reequilibrar el estado financiero de la cadena privada de televisión chilena: "Hoy somos puro músculo, todo el mundo hace varias cosas al mismo tiempo, es cierto, estamos todos estresados, pero ese es el estado de las cosas en este mundo de hoy" (Orellana y Cabello, 2019). En Estados Unidos, el periodista Dean Starkman (2010) hasta habló de "hamsterización" de la profesión, para caracterizar la aceleración del quehacer periodístico. Daría entonces la impresión que es una representación asumida y vehiculada por los mismos practicantes.

Estos casos peculiares, anclados en épocas distintas en todas sus dimensiones, justifican que nuestro enfoque histórico no siga una cronología continua. Se convoca en cada etapa ejemplos y fenómenos anteriores y/o posteriores para reconstruir las escenas de la reactividad periodística. Así, tres etapas parecen decisivas para rastrear las transformaciones de la idea de reactividad en el campo periodístico. En la primera, se dibuja la mercantilización de la idea de reactividad periodística, como una temporalidad burocrática y profesional que proyecta el día siguiente. En la segunda, se transforma en una estética realista del "tiempo real", en la tensión entre notas altamente perecederas y continuidad del flujo de noticias. La tercera etapa es la época de la actualización periodística, en la que se opera un montaje de la inmediatez que asume la imitación cumulativa de la viralidad como capacidad de adaptación al entorno. A partir de estas tres etapas, se puede sondear la dimensión política de la reactividad periodística.

8 Esta última es más relevante cuando se toma en cuenta que el showrunner es un antiguo periodista (David Simon).

9 Lo indica un reportero del tabloide de centro-izquierda El Clarín en una entrevista semidirigida (Faure, 2014): "Cuando había algo ya nos dábamos cuenta, porque el otro partía desde allá... mira este, llamábamos a los otros, oye, averíguate que pasó; entonces, salíamos en los autos corriendo uno detrás del otro, el otro en la moto y etcétera". 


\section{LA REACTIVIDAD PERIODÍSTICA DEL DÍA SIGUIENTE}

A finales del siglo XIX e inicios del siglo XX, la formación de un mercado mediático conlleva una temporalidad propia y sus metas de reactividad. Así, la historia chilena de este mercado muestra cómo se impone la idea de inmediatez, y sedimenta ciertas rutinas que todavía podemos reconocer hoy en el proceso de fabricación de las noticias.

La frecuencia de publicación está en juego en el siglo XIX, bien lo muestra uno de los primeros registros sistemáticos de los periódicos chilenos, el cuadro sinóptico de Ramón Briceño (1886) que identifica la regularización temporal de los periódicos. No obstante, con la masificación del espacio público y la constitución de empresas mediáticas en el cambio de siglo, se asume que el mercado mediático dicta el ritmo y las demandas. Así, la frecuencia de publicación se estabiliza entre los diarios, cuyo nombre se vuelve performativo, y las revistas pueden ser semanales, quincenales o incluso mensuales. Sobre la base de esta regularidad, se amplían y se diversifican las publicaciones y los formatos, y se desarrollan estrategias de rentabilidad "más conscientes de sí" (Ossandón y Santa Cruz, 1998: 14). Como consecuencia, el género informativo se expande en el espacio (más voluminoso) de la prensa, y se enfoca el trabajo "en la novedad, el avisaje y los "accidentes" de la cotidianidad urbana" (Ossandón y Santa Cruz, 1998: 14). Y la ideología se encierra en el editorial. En este periodo histórico, la reactividad periodística se centra en lo inédito, empezando su trabajo de mutación del sentido del evento mediático.

El marco preciso en que se instalan estas transformaciones resulta particularmente original: una temporalidad industrial orientada hacia el producto, y que funciona como un dispositivo de normalización de rutinas y comportamientos para alcanzar la publicación en el tiempo dedicado (diario, semanal, etc.). Estos rasgos se hacen visibles en la consolidación de lo que Ossandón y Santa Cruz llaman las "narrativas estandarizadas o géneros propiamente periodísticos y los profesionales de la prensa" (Ossandón y Santa Cruz, 1998: 14). Dicho de otro modo, la reformulación de la reactividad tiene 
que ver con el proceso de masificación del espacio público, de mercantilización del impreso y de consolidación de un campo periodístico autónomo: se proyecta hacia el día siguiente sobre la base de productos estandarizados que corresponden a estrategias comerciales.

La selección de la información se institucionaliza en un proceso lineal que fija varias etapas y plazos en el cotidiano periodístico (los deadlines), desde la reunión de pauta hasta la composición de las páginas, pasando por el contacto con las fuentes, la escritura, etc. La pauta escrita del próximo boletín evoluciona en las distintas etapas de producción mediática, estando sometida a la lógica de la jerarquización de las noticias y de los puntos de vista recolectados (Alsina, 1989). Opera además a través de la diagramación y de la codificación de las formas (colores, tipografía, ilustraciones etc., en el caso de la prensa).

En el caso chileno, el trabajo mediático de constitución de una agenda de temas se burocratiza a lo largo del siglo XX, para adoptar una forma consolidada en la segunda mitad de este (Salinas y Stange, 2015). La automatización de los criterios de valoración (poco institucionalizados y autoconformados por los mismos profesionales a través de la formación y la socialización al oficio), la mecánica relación con fuentes familiares (y generalmente institucionales) como las normas de redacción (la pirámide invertida, que destaca lo importante y novedoso de manera sistemática) muestran cómo se busca racionalizar la temporalidad mediática para manejar lo imprevisible. Así, se conforma y sigue vigente (más allá de los regímenes políticos, cf. Faure, 2016), un sentido de la reactividad condicionado por una lógica de competencia enmarcada en el proceso rutinario y reiterativo de producción, ${ }^{10}$ en directivas legales, ${ }^{11}$ en la coregulación del campo por el Estado y los profesionales y en un discurso ético

10 A través de la pauta o de la "circulación circular de la información", observada por el sociólogo francés Pierre Bourdieu (1996).

11 Observable en la regulación inicial del sector televisivo, antes que fuera privatizado. 
basado en la tan reivindicada responsabilidad social de los años $1960 .{ }^{12}$ Sobre la base de esta reactividad mercantil y burocrática, se distingue normativa y culturalmente el buen periodismo del malo (Gomis, 1991).

A través de la masificación del espacio público, la fragmentación del mercado obliga a cierta reactividad que fuerza a los periodistas a seguir el ritmo de los eventos para reportearlos mientras publican teniendo como horizonte el día siguiente. La temporalidad burocrático-profesional consiste entonces en racionalizar el tiempo de fabricación de los medios, y enmarca la reactividad en ese proceso de programación del futuro próximo, para tener las noticias listas al fin del día. Dicho de otro modo, publicar el día siguiente las noticias de ayer. En varios casos, tanto fuera (a propósito del New York Times, ver Usher, 2014) como en Chile (pensemos en El Mercurio o en La Tercera), el impreso sigue siendo el lugar donde se expresa la autoridad de la prensa. Esta es la lógica de competitividad que está secuenciada por los plazos (deadlines) y las distintas ediciones. A partir de esta base, que sigue sedimentada hoy día, se desarrolla lo efímero del directo audiovisual y la permanencia del flujo de noticias, que tienen un efecto de realidad.

\section{LA REACTIVIDAD DEL "TIEMPO REAL" EN UN CICLO 24/7}

Hasta las orillas del siglo XXI, el trabajo de constitución de una agenda de temas y la fabricación de marcos de interpretación han rutinizado las prácticas y los comportamientos periodísticos. $\mathrm{Y}$ ha ganado eficiencia con las mutaciones del mercado noticioso, ya sea según la lógica de concentración de la propiedad y de la publicidad (Sunkel y Geoffroy, 2001) así como por una política pública de comunicación sin política, es decir, de libre-mercado (Munizaga, 2004). Esta eficiencia opera en la rapidez de funcionamiento de los medios de comunicación, en la extensión del tiempo de programación y en

12 En términos gremiales, la profesionalización pasa primero por la formación de organizaciones gremiales como el Círculo o el Colegio de periodistas, y solo posteriormente se traduce en la conformación de sindicatos como la Asociación nacional de periodistas. Se opera también en la apertura de formaciones universitarias (desde 1953 en Chile) (Faure, 2016). 
la intensificación de la frecuencia de publicación.

En Chile como en el mundo, la suscripción a los cables de agencias de prensa que aparecen a mitad del siglo XIX, es probablemente la práctica que mejor representa el cruce entre los distintos fenómenos que gestionan una redefinición de la reactividad periodística. Por una parte, la producción y transmisión de noticias cortas a unas empresas periodísticas distribuidas por el orbe favorece la masificación del mercado mediático, objetivando lo noticioso en lo novedoso. Así, por ejemplo, la pirámide invertida fue usada de manera intensa dentro de las agencias y su mano de obra poco calificada, pues permitía lograr una mayor eficiencia en la transmisión de noticias, en particular en casos de urgencia (Sánchez, 1993).

Por otra parte, las agencias de prensa se enfrentan a una paradoja, entre la continuidad del flujo de noticias y el carácter cada vez más efímero de las informaciones incluidas en cada cable. Actúan por tanto según una lógica de directo diferido donde los corresponsales se encuentran en los límites del evento, como prueba de la capacidad de testimonio a corto plazo. Existe, entonces, un paralelismo entre esta puesta en escena de una reactividad diferida cortoplacista y continua (el flujo ininterrumpido de cables), el horizonte del día siguiente de las empresas mediáticas del siglo XX, y la puesta en escena que realiza La Aurora de Chile a inicios del siglo XIX, en la carta evocada al principio del texto. Este paralelismo consolida la idea de un periodismo que se opera a partir del testimonio vivido. Pero se distingue además una modificación de la lógica de la operación. El servicio que proponen las agencias garantiza un flujo inmediato, permanente, abundante de noticias a las salas de redacción en base a la fe en el testimonio periodístico.

El proceso de fabricación de las noticias se ejerce cada vez con mayor velocidad, sirviéndose de nuevos recursos tecnológicos como la imprenta offset (introducida en 1971 en Chile). Con otras capacidades tecnológicas y materiales, como la emisión radiofónica y audiovisual, la frecuencia de publicación se multiplica de manera exponencial. A tal punto que una parte de las "resistencias" mediáticas de la esfera pública plebeya, consiste en salir de los ciclos de producción y proponer publicaciones sin frecuencia 
identificable (además de un cierto anti-profesionalismo y fuentes alternativas). Este fenómeno se observa con mucha claridad en la explosión de folletos y boletines de los cordones industriales que se producen en Chile durante el periodo de la Unidad Popular (1970-1973). Ya la industrialización del flujo de noticias y su inmediatez hacen problema, en el sentido de que son objetos de conflicto. Y sigue siendo el caso durante el régimen autoritario, entre publicaciones clandestinas irregulares y prensa de contra-información de los 1980 que se impone una frecuencia (Apsi, Análisis, Cauce, Fortín Mapocho, La Época, Hoy, entre otras).

Sin embargo, la diversificación de los plazos de publicación incrementa la aceleración del mercado noticioso. Los ritmos de la prensa tradicional se diversifican, por un lado, con la aparición de los bi-semanales, los bimensuales, los trimestrales, los semestrales, etc. Por otro lado, el día mediático se segmenta también en varios momentos de publicación: mañana y tarde para la prensa; mañana, medio día y noche para los noticieros radiales o televisivos. Pero, en el espacio audiovisual, esos momentos de noticias se van a extender en varios plazos durante la jornada periodística. Este fenómeno puede parecer ahora de la mayor normalidad, pues en nuestro tiempo, las radios proponen un noticiero cada hora o hasta cada cuarto de hora, sin embargo, esta lógica informativa se expande incluso hacia géneros mediáticos que, por principio, estarían lejos de lo informativo, como los programas de diversión.

Todo esto contribuye a incrementar la sensación de rapidez, abundancia y permanencia del flujo noticioso. Y esos cambios temporales modifican el sentido de la reactividad periodística que, de la inmediatez del día después, pasa a ser un principio del proceso continuo e ininterrumpido de producción de información. A través de esa intensificación del trabajo periodístico, las noticias pierden valor temporal y, por tanto, económico y social. Se vuelven altamente perecederas, desde las lógicas de contenido siempre nuevo, o "fresco" (nos referimos aquí al principio de fresh news). La vida de una noticia se fragmenta al corresponder a la programación del medio de comunicación, es decir, un día para un diario o una hora para un noticiero televisivo. El carácter mercantil de la noticia obliga a la reactividad, puesto que la difusión solo tiene valor en el 
momento que la noticia desaparece. En este momento, esta revela la atención que ha producido de parte de las audiencias. Entonces, la newsworthiness ${ }^{13}$ no solo consiste en fabricar una noticia tal como tiene que ser según las normas profesionales, sino que consiste además en realizar este ideal en el menor plazo posible para movilizar y retener la atención de los consumidores de las noticias. A mayor distancia temporal de la noticia con el evento que relata, menor su valor de rating y de publicidad. La lógica de mediatización es efímera de manera intrínseca: poco importa los intervalos institucionales y/o tecnológicos entre dos momentos de publicación, el ritmo mediático los equipara a un proceso rápido que toma valor por el desvanecimiento de las noticias en la velocidad de los mismos plazos de producción, y en la atención que engendra.

En consecuencia, la lógica de reactividad es efímera y se focaliza sobre el pasado-presente. Sobrevalorizado, el instante como hecho bruto provoca confusiones en la definición del evento, entre relato del evento y evento del relato (Derrida y Stiegler, 1996). El evento mismo de la enunciación se homogeneiza y se neutraliza con lo efímero de las noticias en un flujo abundante, permanente y frecuente. La reactividad consiste entonces en ganar tiempo y tener la capacidad de reaccionar a los cambios del entorno, según lógicas primariamente económicas para vender "tiempo de cerebro humano disponible" en la reformulación de la economía de la atención que propuso Patrick Le Lay, el CEO de TF1 (Francia, 2004). ${ }^{14}$ Lógica que se puede extrapolar al caso de los mercados noticiosos occidentales en general, y chileno en específico.

Lo efímero se refuerza con la introducción de los programas en directo como parte de la programación radial y televisiva. Con estos nuevos dispositivos mediáticos, se adorna la reactividad de cierto realismo, es decir de una representación estrictamente fiel a lo que está pasando gracias a la

13 Es decir, el valor de la información a los ojos del periodista (Gans, 1980; Tuchman, 1978).

14 "Ce que nous vendons à Coca-Cola, c'est du temps de cerveau humain disponible", L'Expansion - L'Express, 9 juillet 2004. Recuperado en: https://bit.ly/3oUYxuU. 
transparencia tecnológica. Para el sentido común, transmitir en vivo remite sin duda a mostrar la realidad tal cual, reproduciendo el mito de estar presenciando los hechos desde el lugar mismo del acontecimiento. Esta percepción objetiva, evidentemente, todo el trabajo técnico de producción que permite construir esta realidad mediática. Los ángulos de grabación privilegiados en televisión, las fuentes (no) empleadas, las diversas negociaciones con los actores de la noticia, todos son elementos claves de los dispositivos mediáticos en vivo.

Esto es justamente lo que sucede en Chile durante la visita del papa el año 1987. La transmisión por cadena nacional está totalmente controlada por el régimen autoritario, buscando con ello construir en vivo la imagen de una comunión entre la población con la Iglesia y el Régimen Militar.

El realismo del directo audiovisual pasa por la puesta en escena de una capacidad de reacción frente a una incertidumbre permanente que las decisiones periodísticas buscan controlar. Las cadenas televisivas después del terremoto de 2010 o durante las masivas marchas del 2011, ${ }^{15}$ demuestran la necesidad de reactividad periodística para enfrentar a este tipo de eventos. A través del dispositivo en vivo, el carácter incontrolable del futuro está siempre reafirmado a pesar de las rutinas y comportamientos normalizados de la reactividad procesual que, en esa perspectiva, sirven para justificar las fallas y legitiman la reactividad. Ya, para los periodistas, reaccionar no significa planificar sino adaptarse al entorno mediático.

Como síntesis, el discurso de la reactividad del "tiempo real" se encarna en la aparición de dos señales de noticias que transmiten más de 20 horas al día, CNN Chile (2008), parte de la red internacional del mismo nombre, y un canal público 24Horas (2009) vinculado a Televisión Nacional. A través de esas cadenas, no solo se percibe cómo el flujo permanente de noticias está imbricado con su carácter efímero, sino que ilustra además cómo el empleo del tiempo real intenta enmascarar la mediatización de un presente siempre

15 Que vimos en vivo, sin usar metodología particular de "observación". "Este texto ha sido enviado para evaluación en mayo 2019. Obviamente, se podría agregar a estos ejemplos, los acontecimientos del octubre chileno de 2019". 
desplazado.

El dispositivo mediático se vuelve más sofisticado, al mismo tiempo que el discurso de reactividad se adapta y exacerba el uso de la imagen, siempre más amplia. Bien lo muestran el uso de la pantalla dividida (splitscreen) con un corresponsal o para poner en paralelo dos eventos simultáneos; las banderolas (banners) donde circulan, debajo de la pantalla, los resultados de deporte, los últimos cables o las consignas que hace falta seguir en caso de emergencia; ${ }^{16}$ la multiplicación de las fuentes en voz superpuesta (esas voces en off casi siempre tienen un origen institucional, son generalmente reiterativas entre los programas del mismo canal, y tienden a generar un grado de familiaridad y cercanía con el telespectador), etc. También la reactividad está integrada en historias que se desarrollan paulatinamente, con incesantes balances y recapitulaciones de la noticia en desarrollo - es decir del pasado más reciente- en forma de escena retrospectiva ilustrada por imágenes y cintas de audio. A través de la repetición de frases como "Aquí en directo de...", así como de menciones "En vivo" y "Última Hora" en la pantalla, la reactividad se muestra en el dispositivo mediático. Todos esos elementos forman el entretejido de un discurso socio-profesional sobre la capacidad de adaptación del periodismo.

En otras palabras, la reactividad se reformula a través de dos efectos mediáticos: un efecto de realidad gracias a la grabación durante el tiempo del evento, y un efecto de tiempo real, mediante la recepción simultánea en una permanente situación de urgencia. En esta puesta en escena de un realismo periodístico, el pasado a largo plazo pasa a ser un peligro; el presente siempre está diferido; y se asume la incontrolabilidad del futuro. Con la mutación de la reactividad, cambia el régimen de veridicción, es decir "el conjunto de las reglas que permiten, con respecto a un discurso dado, establecer cuáles son los enunciados que podrán caracterizarse en él como verdaderos o falsos" (Foucault, 1992: 43).

El flujo continuo y presentista de imágenes, ya sean metáforas o

16 Pienso en los atentados de París de noviembre 2015, o en días de manifestaciones. 
ilustraciones, reemplaza los criterios enunciativos de la credibilidad que funcionaban en la temporalidad de una prensa burocrática. La velocidad de publicación mediática de estas imágenes es el principal criterio de validez en el mercado noticioso, como lo comprueban los estudios cognitivos de los sesgos de producción y apropiación de las noticias, así como lo demuestra un fenómeno como el miedo de perderse experiencias que otros viven ("Fear of Missing Out" o FoMO) y su directa consecuencia sobre los déficits atencionales frente al flujo de noticias (Przybylski, Murayama, DeHaan, Gladwell, 2013). Estos dos últimos fenómenos se agudizan con la hiperaceleración digital del mercado noticioso y de las sociedades.

\section{LA REACTIVIDAD DE LA ACTUALIZACIÓN}

En la competencia actual, la idea de reactividad se organiza según las sedimentaciones de la reactividad burocrático-empresarial y de la reactividad del tiempo real; no obstante, se reformula en su vínculo directo con la actualización de un flujo de noticias acelerado y voluminoso, con noticias altamente perecederas. Así se extrae de las cronologías invertidas que proponen los sitios web de los diarios, los blogs, Facebook, Twitter: lo que vale, lo que queda, es la última publicación. En las noticias online así como en el uso de las redes sociales virtuales, el horizonte temporal resulta irreductible. Pues, mezcla una frecuencia frenética e irregular. En esta urgencia, alimenta el volumen y la rapidez del flujo de noticias, donde se crea el riesgo permanente de un evento, un futuro incierto, y se incita al periodista a desarrollar su capacidad de adaptación, es decir, de reactividad.

La credibilidad de los periodistas reside en la capacidad de actualizar sus contenidos. En el ámbito noticioso, se privilegia los cambios del entorno por sobre la estabilidad del proceso productivo. Con los sitios de prensa digital y las redes sociales virtuales, el tiempo de vida es equivalente al posteo de una noticia fresca apenas esté posible (es decir as soon as possible, cf. Usher, 2014: 121). Cualquier usuario puede constatar el valor central de la reactividad periodística, ya sea en la rapidez de publicación de las notas como en la puesta 
en escena de actualizaciones progresivas de una nota online a lo largo del día o hasta después de varios días. La huella del discurso de reactividad se expresa en un nuevo dato que se incluye, en el portal como en la página de la noticia, debajo del título y presenta la fecha y la hora de publicación inicial. Al lado, aparece poco a poco la hora de la última actualización de esta misma nota (figura 3). En complemento, se indica el estado progresivo de la noticia adjuntando "[Actualización]" o "[En Desarrollo]” a los títulos o al fin de esta.

Figura 3: Una muestra de una mención "actualizado" de El Mostrador elmostrador Noticias Mercados TV

m. Noticias

Viernes, 27 de mayo de 2016 | Actualizado a las 03:47

Fuente: www.elmostrador.cl

Esta tendencia viene a transformar radicalmente las prácticas y los comportamientos de los periodistas. Abre primero, la pregunta por el golpe periodístico y la exclusividad, dado que la continuidad del flujo ofrece la posibilidad a la competencia de reaccionar, y contraatacar haciendo pasar nuevos desarrollos de la misma noticia como el scoop. El desafío estratégico reside entonces en cuándo publicar una exclusiva.

A la vez, un profesional reporteando puede por ejemplo llamar a sus colegas de la sala de redacción, comunicar los elementos más importantes e inmediatamente después, editar velozmente los primeros elementos de la noticia, gracias a la interiorización previa de rutinas formales. De este modo, el periodista podrá nutrir, reescribir la noticia a lo largo del día o hasta de cambiarle el ángulo. Es lo que muestra muy acertadamente Tomás Dodds, en el caso del reporteo con WhatsApp en La Tercera y Teletrece, el noticiero de la cadena privada Canal 13 (Dodds, 2019). Esta aplicación de mensajería instantánea en Smartphone permite cierta reactividad en el mismo proceso de 
publicación. Un proceso similar se observa en el New York Times, según un estudio etnográfico de referencia (Usher, 2014: 53-64).

Este protocolo se podía observar, de manera escasa, en las sucesivas publicaciones de un diario, un día tras otro; pero ya no es excepción sino regla que cambia los estándares de calidad integrando la legitimidad de corregirse. Es decir que una misma noticia ya no "pertenece" a uno o varios periodistas, que tendrían un monopolio sobre el asunto en la sala de redacción, sino que ingresa en un proceso de "producción des-integrado" (Zeller y Hermida, 2015). Sin mencionar los efectos de retroalimentación que ofrece la tecnología, a través de los que se promueve la interactividad con las audiencias (Usher, 2014).

La lógica que atraviesa la rutina periodística, en su dimensión práctica, cultural, así como económica, remite al trabajo en curso (work-in-progress). Los valores que destaca son la adaptación, la agilidad y la rapidez de decisión. A la vez, esta capacidad de corregirse y cambiar las notas ofrece reactividad frente a decisiones contestadas, a las que se puede intervenir más rápida y fácilmente. En definitiva, el acomodar, el evolucionar o el experimentar proceden, en la reactividad periodística digital, desde la urgencia del mercado noticioso y ya no a partir de la temporalidad institucionalizada del proceso de producción.

En la reformulación de la reactividad como capacidad de actualización, los periodistas están obligados a diversificar sus prácticas más allá de sus cánones iniciales de habilidad, en la lógica de la integración (embedded) en la que se puede siempre añadir un nuevo vínculo a través de la hipertextualidad. El periodista de prensa debe tener hoy en día las competencias para enmarcar fotos y videos en una noticia en línea, o usar líneas de tiempo y mapas interactivos, como remitir a un contenido de otros alcances, producido por otros profesionales, otros sectores sociales o las mismas audiencias activas (Jenkins, 2006). La fabricación de estos documentos es cada vez más parte de sus responsabilidades. Las prácticas se multiplican, las viejas rutinas cambian de sentido debido a los nuevos formatos y los recursos tecnológicos disponibles. Confirman esta tendencia, los ejemplos de periodistas conociendo 
las bases de la codificación en los conjuntos internacionales de medios (Küng, 2015) o las capacitaciones que propone Google a los periodistas, para ocupar las herramientas digitales de Google Analytics. ${ }^{17}$ El montaje de las noticias articula texto, imágenes y oralidad, como la televisión, pero además instrumentos de representación interactivos. La lógica consiste en adaptar, de manera fluida, la forma a las necesidades del mensaje y de las audiencias. La reactividad se muestra también en la variabilidad de los formatos y su relación al desarrollo de las noticias.

Paradójicamente, esos múltiples recursos disponibles no parecieran influir sobre la relación fundamental que establecen los profesionales con sus fuentes. La rutina periodística institucionalizada e internalizada no solo sigue presente, sino que se está re-articulando, no sin conflictos, en esta reactividad que procede desde la urgencia del mercado noticioso. Por ejemplo, WhatsApp ofrece la posibilidad de una relación rápida, directa y 24/7 con las fuentes institucionalizadas (Dodds, 2019). Sin embargo, no se observan cambios cuando se toma en consideración cuántas fuentes son movilizadas en una nota o el tipo convocado de fuentes, mayoritariamente oficiales y hegemónicas (hombres, blancos, de clase alta). La participación de las audiencias se ejerce también como una presión externa, no opera todavía en la continuidad del flujo de noticias.

Esa resistencia de la rutina periodística se relaciona más intensamente con la presión temporal que con la credibilidad de las fuentes. En ese sentido, la función de filtro que selecciona las noticias y les da importancia periodística (la función de gatekeeping) ya no parece central para el trabajo periodístico. Sin desaparecer, opera bajo otras coordenadas, persigue otra meta: montar la inmediatez periodística en formatos multimediáticos y alimentar el flujo en noticias actualizadas.

El realismo periodístico resignifica la inmediatez a partir de la construcción de otro "tiempo real". La actualización condiciona, bajo una

17 Pudimos asistir a una sesión del Google News Lab en Santiago de Chile, el 22 de agosto de 2017. 
lógica performativa, la percepción de una estética realista del hecho, ya no solo actual, sino renovada. El uso cada vez más importante del video refuerza esa estética realista como discurso ficcional sobre la realidad a través de la imagen documental en movimiento (más aún si es un contenido generado por un usuario). La reproducción de esta estrategia alimenta la impresión de vivir lo ocurrido mientras ocurre, ubicando en un segundo plano la reflexión sobre las condiciones de mediación del evento, tal como era el caso con los programas en vivo. El paulatino uso periodístico de grabaciones improvisadas por los seguidores de Twitter durante el evento contribuye claramente a esa estética realista. Su uso es condición de posibilidad en un medio profundamente corporativo que alerta en permanencia sobre el riesgo que amenaza la libertad de expresión. De esta forma, la reactividad representa la imagen omnipotente del gesto de mediatización, que toma realismo en el tiempo real de la actualización.

El uso de las "redes sociales virtuales" para convocar a la "comunidad" de seguidores a "reaccionar", 18 moldea las relaciones entre periodistas y audiencias. En las cuentas Facebook y Twitter de las redacciones mediáticas, los principales mensajes pertenecen a dos tipos de noticias: lo inédito de las mal llamadas "tendencias" (trending topics), y las noticias de última hora sobre eventos que irrumpen el curso clásico de la producción de noticias. La reacción de los seguidores representa una posibilidad de participación de los públicos, aunque también es el resultado del trabajo de incitación de los profesionales, quienes preguntan y sondean "en vivo" las tendencias de los temas que se están hablando, o proponiendo apuestas y sorteos con regalos. Esa estrategia centrada en la oferta rearticula las relaciones entre periodistas y públicos, justifica la creación de nuevas prácticas como las de los gestores de comunidad en línea (community managers) y supone un incremento en la capacidad de interaccionar rápidamente. En términos temporales, se busca un desplazamiento mínimo en las respuestas, los comentarios y otras

18 Práctica introducida por las emisiones con llamada del público. 
críticas, siguiendo la estética del tiempo real. ${ }^{19}$ En el mismo movimiento, se apuesta a generar tiempos de consulta de las noticias, para vender avisos comerciales. Si bien este refinamiento de la economía de la atención muestra una transformación en los metrics, los criterios son muy bajos dado que el objetivo es que los lectores se queden más de un minuto en las páginas.

El imperativo de reactividad cataliza entonces el flujo de noticias y diluye los roles sociales en identidades polifónicas, contribuyendo a la consolidación de un régimen de viralidad (Boullier, 2014). Se opera en un mundo numérico que posibilita una permanencia y un ritmo desenfrenado de circulación de los productos mediáticos. La auto-mediatización de parte de ciertos individuos muestra la interiorización del imperativo de reactividad, ejecutado con inmediatez. La tensión entre la velocidad y lo efímero, se complejiza con la huella indeleble que cada usuario deja en internet, tal como lo analizan las teorías del Big Data. El mejor ejemplo de esta tendencia reside en la forma de circulación de los llamados "memes". Un ejemplo de este uso es el que ocurrió con la campaña de Obama en 2008, pues la atención pública se focalizó sobre esos documentos en momentos breves, la intensidad de esa atención subía y bajaba de manera muy abrupta (Leskovec, Backstrom y Kleinberg, 2009).

En este régimen de viralidad, lo que está en juego son las huellas que deja el gesto mediático y las "réplicas" que engendra, entendidas como "imitaciones en el sentido tardiano" (Boullier, 2014: 20) o, mejor dicho, como oposiciones y adaptaciones. Estas huellas y réplicas toman sentido al momento de alimentar un tráfico de noticias, ya sea el volumen del flujo, su velocidad y su dispersión espacial. Las plataformas de noticias digitales se orientan hacia la maximización del compartir como círculo virtuoso a corto plazo, dado que la novedad es efímera y las noticias altamente perecibles.

19 Como evidencia, fue muy llamativo escuchar a Víctor Herrero, cofundador del sitio de ciberperiodismo Interferencia entregar el promedio de «demora» en responder a los correos y los posts de las audiencias (23 minutos), ¡durante el seminario Swipe!, en la Universidad Finis Terrae, 08/05/2019. 
La actualización como lógica de reactividad, supera las rutinas periodísticas y la rapidez de las decisiones. Opera en el mismo mercado mediático y en la organización de las mismas empresas. El leadership se juega sobre la capacidad de los jefes de redacción, en un entorno moviéndose y cambiando rápidamente, de alertar y redefinir la estrategia digital según las tendencias que observa y la posición de la empresa en el mercado.

Al enfocar la reactividad hacia la viralidad, la categoría misma de "noticia" resulta lesionada, dada la existencia de múltiples gestos de publicación que no remiten necesariamente al proceso de fabricación, sino a prácticas de imitación cuya norma reside en la permanente capacidad de adaptación al mercado noticioso. ${ }^{20}$ Las noticias deportivas ilustran perfectamente el fenómeno, tanto por su cantidad, la diversidad de sus productores como por sus formas y contenidos similares: se replican las noticias entre los clubes que manejan su propia comunicación (con sitio web, conferencias de prensa, etc.); los diarios generalistas como especializados; los hinchas que se organizan y abren cuentas dedicadas a la actualidad de su equipo favorito, entre otras. La noticia de la lesión de un jugador de fútbol muchas veces circula por imitación viral, reduciendo su plusvalía informativa. En el gesto de actualización y su estética realista, el montaje de la inmediatez opera por imitación desenmascarada. La reactividad se vuelve así una política temporal.

\section{LA REACTIVIDAD, ¿UN IMPERATIVO POLÍTICO?}

Los aspectos políticos de la reactividad surgen sin que el investigador los busque de manera directa. En términos temporales, al reenfocarse en el presente, la reactividad impone un futuro imprevisible y un pasado peligroso. Enmarca la acción política en posibilidades restringidas e incidiendo en el sentido de la comunidad política. La mutación profunda de la política temporal de los medios de comunicación también se observa en las dificultades que genera la reactividad para percibir el evento entre los acontecimientos,

20 Hace eco a la crítica de Bourdieu (1996) sobre la circulación circular de la información. 
y distinguirlo del relato y del proceso de mediatización de las sociedades. El flujo hambriento de noticias relativiza los criterios de selección de las noticias, y neutraliza la diferencia editorial entre las instituciones mediáticas. Finalmente, la expansión de la lógica de competencia reformula la reactividad en torno a la mediación transversal del mercado. En este sentido, la reactividad minimiza la responsabilidad socio-profesional de los periodistas y de los actores mediáticos.

El carácter político de la formulación actual del imperativo de reactividad se expresa en la lógica de competencia. En términos históricos, es el resultado de un proceso de "neoliberalización" del mundo, entendido como nuevo paradigma de gestión de los individuos y de las poblaciones como empresarios de sí, que emerge en los años 1970 y del que Chile es un laboratorio. Desde un punto de vista social, la reactividad se enuncia como una nueva manera de plantear la eficiencia política: ya no se trata de racionalizar la organización de la sociedad, sino que se desarrolla por la capacidad de actuar rápidamente en respuesta al entorno (Martuccelli, 2008). ${ }^{21} \mathrm{El}$ mismo sociólogo, en conjunto con la socióloga Kathya Araujo, usan una metáfora que aclara esta lógica: la acción pasa de la planificación "río arriba" a la reacción “corriente abajo", tras la mediación del mercado (Araujo y Martuccelli, 2013).

La reactividad en clave mediática se vuelve también una variable de la actividad de comunicación política tanto de parte de las élites y de las instituciones, así como de los movimientos sociales. Recientes y convincentes trabajos muestran cómo los agrupamientos de desobediencia civil se someten a las lógicas mediáticas (Cervera Marzal, 2016), que se deben leer a nuestro juicio desde el imperativo de reactividad. Finalmente, es la centralidad del mercado y de la competencia la que se formula bajo este criterio: el actor más competente es el más reactivo.

Este imperativo supera el mercado noticioso y la comunicación política. Lo encontramos en el imperativo de reactividad en los programas

21 Martuccelli nunca habla claramente de neoliberalismo en este artículo, sino de "imaginería de la reactividad". Pero trabaja esa categoría de análisis desde el caso chileno en otro artículo (Araujo y Martuccelli, 2013). 
de desarrollo promovidos por el Banco mundial o el FMI. También aparece transparentemente en los programas de mejoramiento de la gestión pública y de los servicios de seguridad o de enseñanza. La reactividad política se vuelve un criterio de evaluación de desempeño de los actores institucionales, ya sean los representantes políticos como los agentes de instituciones híbridas públicoprivadas. Es una reformulación de la responsabilidad institucional que muestra la eficiencia política frente a las preferencias colectivas. En ese sentido son reveladoras, las demandas de "reactividad" que formulan los usuarios de las instituciones sociales, en Francia por ejemplo (Pélamourgues, 2010).

Frente a ese panorama, Martuccelli muestra que la reactividad es una imaginería. De manera concreta, subraya las diferencias entre el discurso ideológico y las prácticas concretas (2008). Y el sociólogo concluye a la mitología darwinista de tal imperativo, que privilegia la capacidad de adaptarse necesaria y exitosamente al entorno social. Sin embargo, pareciera que la reformulación de las lógicas de gobierno en términos de reactividad ya es suficiente para buscar entender en qué mundo estamos viviendo, y cuál es la actualidad de ese mundo. Así, el imperativo de reactividad muestra cómo la gubernamentalidad, sus dispositivos, procesos, tecnologías y técnicas cambian; y de qué manera se redefine el riesgo social.

Para concluir, hace falta formular tres preguntas inherentes a este texto: ¿En qué medida el estudio de la reactividad periodística aporta a esta discusión sobre la regulación de la población y de los individuos? En el movimiento interpretativo contrario, ¿cuáles son las repercusiones de este imperativo político sobre el quehacer periodístico y el campo de las comunicaciones? Tercero, ¿cuáles serían las posibilidades analíticas y los desafíos que plantea el enfoque de las temporalidades periodísticas?

En el entretejido del discurso socio-profesional sobre la capacidad de adaptación del periodismo, el mito de la comunidad muestra en el campo mediático otra manifestación de su transformación hacia un conjunto de usuarios que reclaman respuestas fluidas y rápidas a sus demandas personales. La necesidad de convocar a las audiencias a reaccionar, así como la cuantificación de estas y de su tiempo de atención, bien muestran cómo 
las salas de redacción construyen las comunidades sobre criterios temporales. Y deja entrever la tendencia a una evaluación, de parte de las audiencias como también de los servicios de recursos humanos, del desempeño tanto institucional (de las salas de redacción) como individual (de cada periodista), sobre la base de las capacidades de actuar de manera reactiva. Una rápida lectura de las ofertas de trabajo en salas de redacción en Estados-Unidos revela que las habilidades multitareas y la capacidad de adaptación están destacadas en las competencias requeridas para contratación como periodista. De manera interna (la profesión) como externa (las audiencias), la reactividad se volvería un dispositivo de regulación de la comunidad.

Por otra parte, el flujo noticioso parece impetuoso, lo que implica imprevisibilidad y riesgo: no se trata de anticipar los hechos, sino más bien de matizar su carácter incierto a través de prácticas y comportamientos reactivos. El imperativo de reactividad adoptaría aquí el carácter de una técnica (para fabricar los productos mediáticos). Una pregunta surge entonces, ¿sigue el periodismo profesional teniendo el monopolio sobre las noticias, y la mediación pública? En otras palabras, ¿guarda la racionalidad de una rutina?

La duda aparece al observar las transformaciones de la reactividad en el quehacer periodístico. La actividad de comunicación política y el mercado noticioso parecen, primero, entregar la imitación de contenidos ya formateados para su circulación rápida, y la relación a las fuentes refuerza los actores socialmente dominantes. En el mismo sentido, pero desde otro lugar, se puede temer que una profesión basada sobre la representación del testimonio vivido, presenciando los hechos desde el lugar mismo del acontecimiento, se vea sustituida por los usuarios que generan contenido (UGC).

Segundo, varios fenómenos propios a la fabricación de las noticias tienden a consolidar estas dudas: la flexibilidad de los formatos en relación al desarrollo de una noticia; la lógica de trabajo en progreso; la posibilidad de acelerar la toma de decisión y de corregirla a lo largo del newsmaking; un proceso des-integrado para producir productos integrados (embedded; hipervinculados, etc.), parecieran poner en riesgo este monopolio. Esta duda se ve reforzada al considerar que la misma profesión ha reformulado el riesgo 
sobre la libertad de expresión. En efecto, se distorsionan las fronteras de lo publicable y del secreto, del on y del off para decirlo de una manera periodística, bajo la necesidad de adaptarse rápidamente al mercado, lo que pone en riesgo el ejercicio mismo de la profesión, y su control por fuerzas exteriores. A la vez, arriesga el pacto con el Estado, que consistía en otorgar la autonomía y la autorregulación al campo periodístico en contra de una ética que no ponga en riesgo el orden y la estabilidad de las sociedades liberales. Para que este pacto quede lo más intacto posible, obliga el campo periodístico a nuevas concesiones ligadas a las nuevas positividades de la reactividad (perder cierto control para ganar visibilidad; postergar o adelantar una noticia exclusiva para controlar el fenómeno de imitación viral; etc.).

La desposesión de las noticias construye la crisis como negativo de la reactividad periodística. La crisis es el horizonte, ya no la deriva del modelo. Opera en un flujo de noticias imitadas y sin fin, que los medios buscan administrar sin resultado, lo que refuerza un régimen de historicidad presentista cuyo futuro es incierto y pasado amenazado. Entre efecto de realidad y efecto de tiempo real, la capacidad periodística de adaptación al entorno disfraza lo diferido de simultaneidad realista como para borrar los fallos pasados y apostar a lo imprevisible (evidencia de la renuncia misma a administrar los flujos de informaciones). Este camino, que pareciera teóricamente potente, necesita indagar el "horizonte temporal" de las noticias, ya sea en su orientación verbal como en el estudio del lugar de la pregunta por el cuándo en los montajes textuales. La percepción del evento se entrampa en la imitación de las noticias, el relato y el proceso de mediatización de las sociedades. Sin embargo, no se opera una tabula rasa, sino más bien una suerte de reconfiguración del campo, con un nuevo juego de repartición de notas en desarrollo, de distribución de una autoridad periodística y de diferenciación entre los dispositivos de información. En este estado de excepción mediático, las posibilidades políticas no son uniformes, pero las alternativas se expresan en los restringidos márgenes de la actualización, de la eficiencia y del realismo, es decir de un criterio reactivo de lo que hace verdad.

La política temporal de la mediatización se integra en esa lógica 
transversal de gobierno. Es particularmente significativo para el caso de Chile, donde el relato de refundación democrática no dice nada diferente: la reactividad es una política según la que el futuro es incierto, y la paz social solo se puede garantizar en el presente. Si no sucede así, se corre el peligro de reproducir los errores catastróficos del pasado (según este discurso social), específicamente polarizar el sistema mediático y amenazar la gobernabilidad del Chile post-dictatorial. Entre líneas, revivir los fracasos de la Unidad Popular como en el ejemplo inicial.

Aquí, la polisemia del concepto de "temporalidades" toma un agudo potencial político. Al rastrear las transformaciones históricas del desplazamiento entre "evento" y "noticia", se revela una práctica profundamente gubernamental pero también la posibilidad de volver a pensar la historia de las comunicaciones más allá de la historia política. Al asumir los anacronismos, las continuidades y las innovaciones temporales del quehacer periodístico, se problematiza la relación cronológica entre pasado, presente y futuro, y se ponen en duda los marcos temporales que imponen los cambios de regímenes políticos (con la concepción del pluralismo que implica). Es el terreno de la lucha entre temporalidades, y de la intervención académica: como hipótesis, el trabajo de actualización periodística abre el espacio de una arqueología temporal de los gestos de mediatización y una genealogía del imperativo político de reactividad al entorno.

\section{REFERENCIAS}

S/A. (2004). "Ce que nous vendons à Coca-Cola, c'est du temps de cerveau humain disponible”, L'Expansion - L'Express, 9 juillet 2004. Recuperado de: https://bit.ly/3oUYxuU.

Alsina, R. (1989). La construcción social de la noticia, Barcelona: Paidós. Araujo, K. y Martuccelli, D. (2013). Individu et néolibéralisme: réflexions à partir de l'expérience chilienne. Problèmes d'Amérique latine, 88 (1), 125-143. 
Boullier, D. (2014). Les sciences sociales face aux traces du big data? Société, opinion et répliques. FMSH-WP-2015-88. 2014. Recuperado de: https://halshs.archives-ouvertes.fr/halshs-01141120/.

Bourdieu, P. (1996). L'opinion publique n'existe pas. París: Editions de minuit. Briceño, R. (1886). Cuadro sinóptico periodístico completo de los diarios y periódicos publicados en Chile desde el año 1812 hasta el de 1884 inclusive, que la Biblioteca Nacional conserva empastados. Santiago de Chile: Imprenta Nacional.

Cervera Marzal, M. (2016). Médiatisation et hiérarchisation du militantisme. Politique et Sociétés, 1 (35), 3-25.

Citton, Y. (2014). Les Lumières de l'archéologie des médias. Dix-huitième siècle, 46 (1), 31-52.

Couldry, N. y Hepp, A. (2013). Conceptualizing Mediatization. Communication Theory, 23, 191-202.

Dayan, D. y Katz, E. (1992). Media Events. The Live Broadcasting of History. Cambridge: Harvard University Press.

Derrida, J. y Stiegler, B. (1996). Artefactualités. En Echographies de la Télévision (pp. 11-65). París: Galilée - I.N.A.

Dodds, T. (2019). Reporting with WhatsApp: Mobile Chat Applications' Impact on Journalistic Practices. Digital Journalism, DOI: 10.1080/21670811.2019.1592693.

Faure, A. (2014). Des(-)ordres journalistiques dans une crise révolutionnaire: chroniques de l'être journalistique chilien durant l'Unité populaire (1970-1973). Thèse de doctorat en Science politique, Sciences-Po Grenoble.

. (2016). "Deuda, Seguridad y Presentismo. La actualización periodística del tiempo cotidiano en Chile (1970-2013)" en Comunicación política y democracia en América Latina, eds. Juan Pablo Arancibia Carrizzo y Claudio Salinas. Quito (Ecuador): Gedisa \& CIESPAL, 151-183. 
. (2017). “¿Contribuyeron los medios de comunicación al golpe de Estado? Otra historia del periodismo durante la Unidad Popular (19701973)". Izquierdas, 35, 71-97. Recuperado de: https://dialnet.unirioja. es/descarga/articulo/6175850.pdf.

Foucault, M. (1971). "Nietzsche, la généalogie, l'histoire". Hommage à Jean Hippolite, Paris, PUF, col. «Épiméthée», pp. ${ }^{\circ} 145-172$. En: Dits et écrits I. 1954-1975, Tomo 2, Texto 84, París: Gallimard, 1004-1025. . (1992). Verdad y Poder, Entrevista con M. Fontana en Rev. L'Arc, $\mathrm{n}^{\mathrm{o}} 70$ especial, 16-26, en Foucault, M.: Microfísica del Poder, Madrid, La Piqueta.

. (2014). Naissance de la biopolitique. Cours au collège de France, 1978-1979. París: EHESS, Gallimard, Seuil (Hautes Etudes).

Gallo, J. (2004). Weblog Journalism: between infiltration and integration. En: Into the Blogosphere: Rhetoric, Community, and Culture of Weblogs, edited by Minnesota Blog Collective. http://blog.lib.umn. edu/blogosphere/weblog journalism.html.

Gans, H. (1980). Deciding What's News. A Study of CBS Evening News, NBC Nightly News, Newsweek and Time. New York: First Vintage Books Editions.

Gomis, L. (1991). Teoría del periodismo. Cómo se forma el presente. Barcelona: Paidós.

Jenkins, H. (2006). Convergence culture: where old and new media collide. New York: New York University Press.

Küng, L. (20156). Innovators in Digital News. London: I. B. Tauris., col. "RISJ Challenges".

Lagneau, E., Nicey, J., Palmer, M. y Rebillard, F. (2013). La dynamique sociale des sources et flux de nouvelles. Introduction. Sur le journalisme, 2 (1). Recuperado de: http://surlejournalisme.com/rev/index.php/slj/ article/view/67.

Lecaros, M. J. y Greene, F. (2012). Editores chilenos y rutinas periodísticas: revisión y propuesta para un estudio sobre el cambio en la sala de redacción. Cuadernos de Información, 30, 53-60. 
Leskovec, J., Backstrom, L. y Kleinberg, J. (2009). Meme-tracking and the Dynamics of the News Cycle. ACM SIGKDD International Conference on Knowledge Discovery and Data Mining (KDD). Recuperado de: http://surlejournalisme.com/rev/index.php/slj/article/view/67. http:// www.cs.cornell.edu/home/kleinber/kdd09-quotes.pdf.

Lévrier, A. y Wrona, A. (ed.). (2013). Matière et esprit du journal. Du Mercure Galant $a ̀$ Twitter. París: PUPS (Histoire de l'imprimé).

Martuccelli, D. (2008). Les imageries du pouvoir: de la rationalisation à la réactivité. L'Homme et la société, 152-153 (2), 183-200.

Munizaga, G. (2004). Las políticas comunicacionales de la Transición. En: Nelly Richard (ed.), Utopia(s) 1973-2003. Revisar el pasado, criticar el presente, imaginar el futuro. Santiago de Chile: Universidad Arcis.

Orellana, G. y Cabello C. (2019). Director ejecutivo de Canal 13: "La crisis de la TV viene de malas decisiones que hemos tomado los ejecutivos". $L a$ Tercera, 29 de marzo de 2019. Recuperado de: https://bit.ly/3nlhNRT. Ossandón B., C. y Santa Cruz A., E. (1998). Entre las alas y el plomo. La gestación de la prensa moderna en Chile. Santiago de Chile: Universidad Arcis, LOM Ediciones.

Peláez y Tapia, J. (1927). Historia del Mercurio. Santiago de Chile: Talleres de "El Mercurio".

Pélamourgues, B. (2010). Les enquêtes de satisfaction dans les caisses d'Allocations familiales. Un outil pour l'amélioration de la qualité de la relation de service. Informations sociales, 158 (2), 76-84.

Przybylski, A. K., Murayama, K., DeHaan, C. R. \& Gladwell, V. (2013). "Motivational, emotional, and behavioral correlates of fear of missing out". Computers in Human Behavior, 29 (4), 1841-1848.

Salinas Muñoz, C. y Stange Marcus H. (2015). Burocratización de las rutinas profesionales de los periodistas en Chile (1975-2005). Cuadernos. Info, 37, 121-135.

Sánchez, J. (1993). La pirámide invertida. Caída de un mito. Cuadernos de Información, 8, 88-95. 
Schelsinger, P. (1977). Newsman as a Time Machine. The British Journal of Sociology, 3 (28), 336-350.

Silva Castro, R. (1958). Prensa y Periodismo en Chile (1812-1956). Santiago de Chile: Ediciones de la Universidad de Chile.

Starkman, D. (2010). "The Hamster Wheel: Why Running as Fast as We Can Is Getting Us Nowhere". Columbia Journalism Review, SeptemberOctober. Recuperado en: https://archives.cjr.org/cover_story/the hamster_wheel.php.

Stephens, M. (2012). History of Newspapers. Collier's Encyclopedia. Recuperado en: https://www.nyu.edu/classes/stephens/ Collier\%27s\%20page.htm.

Sunkel, G. y Geoffroy E. (2001). Concentración económica de los medios de comunicación. Santiago de Chile: LOM Ediciones.

Tuchman, G. (1978). Making News. A study in the construction of reality. New York: Free Press.

Usher, N. (2014). Making News at The New York Times. Ann Arbor (MI, USA): The University of Michigan Press, col. "The New Media".

Valdebenito, A. (1956). Historia del Periodismo Chileno. Santiago de Chile: Imprenta Fantasía y Colegio de Periodistas.

Zaller, J. (1999). A Theory of Media Politics: How the Interests of Politicians, Journalists, Citizens shape the News. Chicago: University of Chicago Press.

Zeller, F. y Hermida, A. (2015). When Tradition meets Immediacy and Interaction. The Integration of Social Media in Journalists' Everyday Practices. Sur le journalisme, About journalism, Sobre jornalismo [En línea], 1 (4). Recuperado de: http://surlejournalisme.com/rev/index. $\mathrm{php} / \mathrm{slj} /$ article/view/202/88. 